\title{
Research on Application of Big Data Technology in University Internal Auditing
}

\author{
Jie Yang ${ }^{1, a}$ \\ ${ }^{1}$ Heilongjiang University of Technology, Jixi, Heilongjiang, China, 158100 \\ aemail,jxdxyj@163.com
}

Keywords: Research, Application, Big Data Technology, University Internal Auditing

\begin{abstract}
Taking information technology means and using big data thinking to improve the quality and efficiency of audit has become the development trend of China's audit practice. The paper analyzes the problems existing in the audit of economic responsibility in colleges and universities, such as weak audit power, backward audit methods and tools, and weak audit independence. With the help of big data thinking and advanced technology, the system is divided into three parts: system and business management, data collection, project implementation. The five modules of audit analysis put forward the information system structure and operation mechanism of university economic responsibility auditing in the big data era. It provides a reference for the new-type information tools such as big data and cloud computing.
\end{abstract}

\section{Introduction}

"Big Data" is a description of massive information and filling information. Today, "big data" is just like the Internet more than a decade ago. It is a new and important concept. The attention from government departments, enterprises and the community is rising. The emergence of large-scale data technology from the human measurement, recording and analysis of the world's desire, the current data technology for large-scale impact on the industry to explore, but also as ten years ago, Internet technology research as hot. From the news business perspective, big data technology is a set of collection, search, query, analysis and processing, visual presentation and a series of data processing tools in one of the practical technology. At present, in the field of news communication, the focus of the industry is mainly focused on the new type of news reporting that the large-scale data technology.

The internal audit of colleges and universities in China is a key component of the management system and internal control of China's higher education. It is also an important guarantee for the healthy and rapid development of China's higher education. On the other hand, the more the development of higher education institutions, the more the internal audit work to strengthen, the more to play to enhance its education system to resist risks, and promote the management level of education and the smooth realization of the goal of education. In recent years, with the rapid development of modern society and the gradual deepening of education reform, the increasingly complex internal and external environment makes the realization of the higher risk of the goal of education, which put forward a higher update of the internal audit work Claim. In the new situation, how to comprehensively enhance their work level, how to transform according to the needs of the development of colleges and universities, has become an urgent need to solve internal audit department.

Audit process is the internal audit work of the specific links and steps, the internal audit departments to effectively fulfill their functions of the bridge. So the core part of the internal audit work is to optimize and improve the internal audit process. As the internal audit as part of internal control, its direct objective is to evaluate the soundness and effectiveness of internal control. Therefore, the optimization of internal audit process should focus on internal control, throughout the entire internal audit process at all stages of optimization, in order to make the audit object more targeted, the audit process more efficient, more clear audit objectives, audit function So as to enhance the level of internal audit work, and better play the role of internal audit functions for the 
healthy, rapid and sustainable development of college education escort.

\section{The Definition of the Big Data}

On the "number" of the discourse can be traced back to the ancient Greek, Greek philosophy, "Pythagorean thought that 'number' is the origin of all things, the nature of all things can be attributed to the number of provisions. In Latin, the word "data" is "known" and can be understood as "fact". The long-standing measurement and recording behavior has led to the birth of data into the information society, where data can be recorded and stored on a large scale because of the widespread use of computers in the binary system. Data types include: numeric, text, byte, etc., pictures, sound, video and other information can also be stored in the form of data.

Today, "big data" to people like the Internet more than a decade ago, is a new and important concept. Since the birth of the computer more than half a century, the information generated by the speed of the accelerating, the total amount of information continues to increase in recent years, the accumulation of information sufficient to achieve the level of lead to qualitative change. First experience the information explosion genetics, astronomy, etc. Big data "concept has been extended to all disciplines, industry. Major data is not a precise concept, at first, it refers to the need to deal with the amount of data is too large, beyond the maximum amount of memory that a typical computer can carry, engineers have had to improve the tools for processing data, which has led to the birth of new processing technologies.

\section{The Concept of University Internal Audit}

In the Audit Commission's Provisions on Internal Audit, the internal audit is described as: "The internal audit is an independent monitoring and evaluation of the unit and its units of financial revenue and expenditure, financial revenues and expenditures, economic activities, the true, legitimate and effective Behavior in order to promote the strengthening of economic management and the achievement of economic objectives ". China Internal Audit Association issued in 2003, "Internal Audit Basic Standards" internal audit is defined as "an independent organization within the objective of the monitoring and evaluation activities, which through the review and evaluation of business activities and internal control of the appropriateness, legitimacy and Effectiveness to promote the achievement of organizational goals." In 2013, China Association of Internal Auditors issued "No. 1101 - Basic Principles of Internal Audit", which revised the definition of internal audit as "an independent, objective confirmation and advisory activities, through the use of a systematic, standardized approach to review and evaluation The adequacy and effectiveness of the organization's business activities, internal controls and risk management to facilitate the organization to improve governance, increase value and achieve its objectives. "

From the above definition, we can see that internal audit from financial audit to management audit, to risk-oriented comprehensive audit of the change, while China's internal audit association in 2013 "No. 1101 - Basic Principles of Internal Audit" on the internal The definition of audit is consistent with the definition of International Institute of Internal Auditors in 2004, which has achieved international convergence. But it is clear that the development of internal audit in our country lags far behind international development.

China Internal Audit Association in July 2009 issued the "Internal Audit Practice Guide No. 4 College Internal Audit", which is defined as the internal audit of colleges and universities, "internal audit institutions and personnel through the school and the use of resources-related business Activities and their internal controls, and to carry out identification, evaluation and consultation to promote the perfection of management control, risk prevention and benefit creation so as to promote the realization of the goals of the school. The Guide defines the internal audit of colleges and universities based on the actual situation of China's colleges and universities, clarifies the subject, scope, objectives and basic duties of the internal audit of colleges and universities, and has important guiding significance for the development of internal audit in colleges and universities. 


\section{The Main Problems in the Internal Control Construction in Colleges and Universities}

The control environment is not satisfactory, including the internal environment and external environment. The external environment is mainly manifested as a lack of uniform internal control standards and supervision mechanism is still not perfect sound, management system and external governance structure flaws, some of the macro policy-oriented bias and so on. The internal environment is the basis for the organization and implementation of internal control, specifically to colleges and universities, including the management of the concept of internal control, management preferences, human resources policy, college cultural awareness and values, although most colleges and universities have developed a corresponding Internal control system, but the internal control is equivalent to a variety of policy documents and systems, colleges and universities for the understanding of internal control is not comprehensive, that the internal control is only a matter of the financial sector and a few departments, is a small number of leadership, Resources are concentrated in teaching and scientific research and other areas, most of the internal control activities carried out after the control, the formation of heavy system construction, implementation of the light system; heavy accounting control, light management control.

It lacks risk assessment mechanism. However, colleges and universities are not aware of the risks they face, especially the lack of sound and effective risk management system. At present, China's universities do not carry out activities related to risk assessment, even a small number of colleges and universities carry out the risk management. But only considering the quantifiable risks related to finance. The risks that are difficult to quantify include operational risk, strategic risk, reputational risk and liquidity risk, which are not only limited to financial risk, but also due to lack of system resulting in increasingly weak risk management.

The diversification of university economy makes the scope of internal control involve many departments such as finance, personnel, scientific research, infrastructure construction, property management, etc. The whole department lacks effective cohesion and mutual containment, and physical management is the soft underbelly of internal management. Low level of management, poor communication, resulting in a serious waste of resources to the traditional method of containment still dominated to reflect the resource base and comprehensive risk control concept of the use of less.

The supervision is ineffective, internal audit functions are limited. The internal audit department of the university is not strong, the function is not given play and the lack of staffing causes the internal control lacks the effective supervision and guarantee.

\section{The Application Research of Big Data Technology in University Internal Audit}

Colleges and universities as a special entity, it has its particularity in the implementation of economic responsibility audit also. According to the internal management, the national laws and regulations, the use of audit methods and methods, the school departments, colleges, logistics groups, school-run entities such as enterprises, and so on. Due to the particularity of colleges and universities, at present, there are still three major limitations in the internal audit of colleges and universities in our country. First, the audit resources, power is weak, and audit requirements do not match; Second, the audit methods, tools, backward; Third, the audit independence is weak. Therefore, with the economic responsibility audit business more and more complex, audit institutions and auditors audit risk is also increasing.

Big data is a collection of massive data, big data technology is from a variety of types of data, the ability to quickly access valuable information. The technology for big data, including large-scale parallel processing database, data mining, distributed database, distributed file system, cloud computing platform, and scalable storage systems. To big data, cloud computing as the representative of the new generation of information technology to flourish, to China's social and economic profound changes, but also to improve the quality and efficiency of the audit, improve the audit methods and techniques, innovative audit methods, reduce audit risk To new tools.

At present, the domestic auditing circles have carried on the preliminary exploration to the big 
data in the auditing aspect application, Gu Hongfei studied uses the data analysis technology in the big data analysis audit data, proposed from the data analysis technology our country how to promote the audit in the big data environment The development of information technology. DING Shu-qin analyzes the audit reform in the big data environment, and further puts forward six suggestions from the macroscopic point of view. Li Jianhe and Wang Chunxin combined big data thinking and technical methods, based on actual audit work, introduced the control of big data, proposed innovative audit methods and audit methods for enterprises to add value. This paper discusses the object and content of government environmental responsibility audit supervision from the perspective of government environmental governance system and government environmental responsibility, analyzes the impact of big data technology on government environmental responsibility audit, and puts forward the countermeasures of government environmental liability under big data background The implementation of the audit path. Qin Rongsheng expounded the impact of big data and cloud computing technology on audit, and put forward suggestions to strengthen the audit application of big data and cloud computing technology. This paper discusses the method, flow and information system of big data visual analysis from the requirements of visual data analysis and practice of big data audit. Sun Zeyu pointed out that in the context of big data, financial reporting audit data will be driven by the concept of change, the auditors can be based on different types of data between the relevance of effective screening of financial reporting of material misstatement risk and inspection risk, based on large volume of data samples Mining of reliable audit evidence, while based on high-speed flow of data validation audit conclusions. From the perspective of China's existing research, from the macro point of view to explore the background of big data audit development trend of China's research more from the micro level of big data on China's audit impact of the literature less, this paper from the economic responsibility audit of the micro- This paper makes suggestions on how to improve the efficiency and quality of university auditing by making use of big data in our university, and makes up for the deficiency of domestic related research literature.

\section{Conclusion}

The auditing information based on big data provides a powerful weapon for auditors in our country. If it is appropriately used in auditing practical work, it will undoubtedly improve the quality and efficiency of auditing staff. Through the information operation can also enhance the independence of the audit work, reduce audit risk and improve the three major limitations of economic responsibility audit of the University.

\section{References}

[1] Jia Xinzhang, Li Jingyuan. China Internal Audit, Vol. 6 (2014) No 53, p.25-26

[2] Peng Sue, Wang Yunhui, Wang Qunyong. Tianjin University, Vol. 12 (2015) No 27, p.74-76

[3] Qian Xiyuan, Jing Jianfen. Friends of Accounting, Vol. 30 (2014) No 19, p.144-145

[4] Wang Kuailiang. Journal of Economic Research, Vol. 29 (2008) No 27, p.21-23

[5] Zhang Gongxu, Sun Jing. Journal of Liaoning Normal University, Vol. 8 (2013) No 27, p.57-60

\section{JieYang Female the Sandong of Heilongjiang province 197905 Bachelor degree lecturer}

